\title{
Comparative performance and haematological profile of cockerel chickens debeaked at varied length and at different ages
}

${ }^{* 1}$ Bolarinwa, M. O., ${ }^{2}$ Adeyemo, G. O. and O. A. Awodele

${ }^{1}$ Dept of Animal Production Technology, Federal College of Animal Health and Production Technology, Institute of Agricultural Research and Training, Moor Plantation,

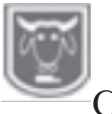
Ibadan

${ }^{2}$ Dept of Animal Science, University of Ibadan, Ibadan, Nigeria Corresponding author: polymeragro@gmail.com; 08030530234; 08075310375

\section{Abstract}

An experiment was conducted to determine the comparative performance of cockerel chickens debeaked at varied length and at different ages. One hundred and ninety-five cockerel birds were purchased from a reputable hatchery, brooded and randomly allotted into 4 treatments of three replicates and 15 birds per replicate. Treatment $1\left(T_{1}\right)$ served as the control which contained 15 birds that were allotted into 3 replicates without debeaking. At the 4 th week, 45 birds were debeaked at varied degrees of debeaking to form treatments 2,3 and 4 respectively as follows: $T_{2}{ }_{2}{ }^{1} /{ }_{2}$ of upper beak and ${ }^{1} /{ }_{2}$ of lower beak debeaked using 5 birds per replicate and 3 replicates per treatment, $T_{3^{-}}{ }^{1}{ }_{2}$ of upper beak and ${ }^{1}{ }_{3}$ of lower beak debeaked using 5 birds per replicate and 3 replicates per treatment and T4- ${ }_{3}^{1}$ of upper beak and $1 / 2$ of lower beak were debeaked using 5 birds per replicate and 3 replicates per treatment as it was done in all other treatments. Also, the same procedures used for all the treatments in the 4th week as demonstrated above were repeated in the sixth, eighth and tenth week of age respectively so as to reflect the treatment effect at different ages. Data collected include: initial and final weight, daily feed intake, body weight gain and of haematological parameters. Results showed that varied degrees of debeaking examined significantly affected $(p<0.05)$ all the performance parameters considered:body weight gain, FCR, heterophil/lymphocyte ratio etc. It was therefore concluded that farmers should imbibe the practice of cutting half of the upper beak and half of the lower beak or one third of the upper beak and half of the lower beak $\left(T_{2}\right)$ preferably at the earlier stages of the birds' life as they gave better values for the performance parameters considered.

Keywords: Comparative performance; cockerels; debeaking; haematological parameters

\section{Introduction}

Beak trimming was developed at the Ohio experimental station in the $1930 \mathrm{~s}$ (Marchant- Forde et al., 2011). The original technique was temporary, cutting approximately $6 \mathrm{~mm}(1 / 4$ inch) of the beak. It was thought that the tip of the beak had no blood supply and presumably no sensation. The procedure was performed by hand with a sharp knife, either when death due to cannibalism was excessive, or when the problem was anticipated because of a history of cannibalism in the particular strain of chicken (Pizzonlante et al., 2011). Chicks and adult birds pecking at each other until blood shows and then destroying one another by feather pecking is a source of great loss in many flocks, especially when kept in confinement. The recommendation of the Ohio experimental station of cutting back the tip of the upper beak has been found to be effective until the beak grows out again (Pizzonlante et al., 2011). In recent years, the aim has been to develop more permanent beak trimming (although repeat trimming may be required). Using electrical heated 


\section{Performance and haematological profile of cockerel chickens}

blades in a beak trimming machine, provides a self-cauterizing cut. There are currently four widely used methods of beak trimming: hot blade, cold blade (including scissors or secateurs) electrical (the BioBeaker) and infrared .The latter two methods usually remove only the tip of the beak and do not leave an open wound, therefore they offer improvement in welfare .Other approaches such as the use of lasers, freeze drying and chemical retardation have been investigated but are not in widespread use (AVMA beak trimming Retrieved HOV-11, 2011).

In the UK, Animal Welfare Council that the accepted procedure is to remove not more than one third of the upper and lower beaks or not more than one third of the upper beak only but went on to recommend: "Where beak trimming is carried out, it should whenever possible be restricted to beak tipping; that is blunting of the beak to remove the sharp point which can be the cause of the most severe damage to other birds. The tendency of cannibalism and feather pecking varies among different strains of chickens, but does not manifest itself consistently. Some flocks of the same breed may be entirely free from cannibalism, while other under the same management, may have a serious outbreak. Mortality due to cannibalism can be up to $15 \%$ in egg laying flocks housed in aviaries, straw yards and free range systems (Keeling et al., 1988). Since egg - laying strains of chickens can be kept in smaller group sizes in cages, cannibalism is reduced leading to a lowered trend in mortality as compared to non-cage system. The objectives of this research were towards evaluating the comparative performance of cockerels debeaked at different ages and with varied degrees of debeaking and also determining the effects of length of debeaking and age at debeaking on the hematological profile of cockerels.

\section{Materials and methods}

One hundred and ninety five (195) cockerels were purchased from a reputable hatchery in Ibadan. The birds were brooded for four weeks. At the end of 4 th week, the birds were randomly allotted into 4 treatments and all the treatments were examined in 4 different weeks as stated below:

Treatment 1: No debeaking (control)

Treatment 2: Cutting of $1 / 2$ of upper beak and $1 / 2$ of lower beak.

Treatment 3 : cutting of $1 / 2$ of upper beak and $1 / 3$ of lower beak.

Treatment 4 : cutting of ${ }^{1} / 3$ of upper beak and $1 / 2$ of lower beak.

Each treatment was replicated 3 times with 15 birds per replicate.

At the end of the 12 weeks of the experimental trial, $5 \mathrm{mls}$ of blood samples were collected from the jugular vein into bottles containing EDTA. The heterophillymphocyte ratio $(\mathrm{H}: \mathrm{L})$ is as calculated below:

$\mathrm{H}: \mathrm{L}=\underline{\text { Heterophil value at age ' } \mathrm{x}}$ Lymphocyete value of age ' $x$ '

Data were analyzed using Statistical Analytical System procedure (SAS, 1988) and means were separated using the new Duncan multiple range test.

\section{Results and discussion}

Table 1 shows that there were no significant differences $(\mathrm{P}>0.05)$ in total weight gain (TWG) and feed conversion ratio (FCR) except for total feed consumed (TFC) which had a significant difference $(\mathrm{P}<0.05)$ between the control (T1) and other treatments. The difference in feed consumption among treatments was due to feather pulling and pecking which led to feed wastage. Also, Table 2 showed that there were significant differences $(\mathrm{P}<0.05)$ among the weeks in terms of TFC, TWG and FCR. 


\section{Bolarinwa, Adeyemo and Awodele}

Table 1: Comparative production performance of cockerels at varied degees of debeaking

\begin{tabular}{llll}
\hline Treatment & TFC & TWG & FCR \\
\hline T1 & $3.95 \pm 0.02^{\mathrm{b}}$ & $1.30 \pm 0.05$ & $3.04 \pm 0.11$ \\
$\mathrm{~T} 2$ & $4.10 \pm 0.03^{\mathrm{a}}$ & $1.35 \pm 0.02$ & $3.05 \pm 0.04$ \\
$\mathrm{~T} 3$ & $4.05 \pm 0.04^{\mathrm{a}}$ & $1.37 \pm 0.02$ & $2.96 \pm 0.06$ \\
$\mathrm{~T} 4$ & $4.11 \pm 0.04^{\mathrm{a}}$ & $1.36 \pm 0.03$ & $3.07 \pm 0.05$ \\
\hline${ }^{\mathrm{ab}}$ : means with different superscripts on the same column are significantly different $(\mathrm{P}<0.05)$. \\
TFC: Total Feed Consumed (kg); TWG: Total Weight Gain (kg); FCR: Feed Conversion Ratio
\end{tabular}

Table 2: Performance parameters of cockerels at different ages of debeaking

\begin{tabular}{llll}
\hline Age of debeaking & TFC & TWG & FCR \\
\hline Week 4 & $3.93 \pm 0.03^{\mathrm{c}}$ & $1.35 \pm 0.02^{\mathrm{ab}}$ & $2.92 \pm 0.06^{\mathrm{b}}$ \\
Week 6 & $4.06 \pm 0.02^{\mathrm{b}}$ & $1.41 \pm 0.03^{\mathrm{a}}$ & $2.93 \pm 0.02^{\mathrm{b}}$ \\
Week 8 & $4.18 \pm 0.02^{\mathrm{a}}$ & $1.35 \pm 0.03^{\mathrm{ab}}$ & $3.10 \pm 0.07^{\mathrm{ab}}$ \\
Week 10 & $4.19 \pm 0.02^{\mathrm{a}}$ & $1.33 \pm 0.01^{\mathrm{ab}}$ & $3.17 \pm 0.04^{\mathrm{a}}$ \\
\hline abc: means with different superscripts on the same column are significantly different (P<0.05). TFC: Total Feed Consumed (kg); TWG: Total \\
Weight Gain (kg); FCR: Feed Conversion Ratio
\end{tabular}

(Table 1) shows that $\mathrm{T}_{2}$ (Cutting of $1 / 2$ of upper beak and $1 / 2$ of lower beak) and $\mathrm{T}_{4}$ (cutting of $1 /{ }_{3}$ of upper beak and $1 / 2$ of lower beak) had better performance for (TWG) total weight gained, (TFC) total feed consumed, (FCR) feed conversion ratio at $4^{\text {th }}$ and $6^{\text {th }}$ weeks of age compared to the treatments of other ages which is in agreement with (Glatz,2005) that partial removal of both top and bottom beaks, reducing approximately $1 / 3-1 / 2$ of the beak's length, and Sub-dermal layers of the beak tissue are typically healed within 3-4 weeks after debeaking (Gentle et al.., 1997; Marchant-Forde et al., 2011).
From Table 3, it was observed that there are no significant difference $(\mathrm{p}>0.05)$ among all the treatments with regards to all the blood parameters except the platelet which shows a significance difference $(\mathrm{p}<0.05)$, with $\mathrm{T} 1$ having the lowest value followed by $\mathrm{T} 4$ and T3 while T2 had the highest value respectively. Low platelet concentration, can cause thrombocytopenia and can be due to either decrease production or increase destruction of platelet while high platelet concentration is thrombocytosis and neither congenital, reactive (to cytosis) or due to unregulated production. All the haematological parameters examined fell within the normal range (Jain-Nemi, 1993).

Table 3: Haematological parameters of cockerels debeaked at varied degrees

\begin{tabular}{|c|c|c|c|c|c|}
\hline Parameters & $\mathbf{T}_{0}$ & $T_{1}$ & $\mathbf{T}_{2}$ & $\mathbf{T}_{3}$ & NHR \\
\hline $\mathrm{PcV}$ & $27.00 \pm 3.21$ & $22.73 \pm 1.14$ & $25.92 \pm 1.30$ & $23.55 \pm 1.21$ & $22.0-35.0$ \\
\hline $\mathrm{Hb}$ & $9.00 \pm 1.80$ & $7.31 \pm 0.42$ & $8.64 \pm 0.43$ & $7.85 \pm 0.40$ & $7.0-13.0$ \\
\hline $\mathrm{Rbc}$ & $3.87 \pm 0.43$ & $3.77 \pm 0.16$ & $3.83 \pm 0.16$ & $4.04 \pm 0.17$ & $2.50-3.50$ \\
\hline Wbc & $18.48 \pm 0.18$ & $20.75 \pm 1.45$ & $19.56 \pm 1.16$ & $18.51 \pm 0.82$ & $12.00-30.00$ \\
\hline Lymp & $55.33 \pm 4.10$ & $62.09 \pm 2.77$ & $54.25 \pm 2.64$ & $63.91 \pm 2.14$ & $45.00-70.00$ \\
\hline Hetero & $37.67 \pm 4.48$ & $30.64 \pm 2.73$ & $38.58 \pm 2.52$ & $30.45 \pm 2.01$ & $15.00-40.00$ \\
\hline Mono & $3.33 \pm 0.33$ & $3.18 \pm 0.26$ & $3.42 \pm 0.36$ & $3.00 \pm 0.23$ & $5.00-10.00$ \\
\hline Eosi & $3.67 \pm 0.33$ & $3.91 \pm 0.46$ & $3.50 \pm 0.45$ & $2.51 \pm 0.28$ & $1.50-6.00$ \\
\hline Baso & $0.00 \pm 0.00$ & $0.19 \pm 0.09$ & $0.25 \pm 0.13$ & $0.09 \pm 0.09$ & - \\
\hline $\begin{array}{l}\text { Platelets } \\
\text { X } 10^{4}\end{array}$ & $12.33 \pm 58.1^{\mathrm{b}}$ & $16.60 \pm 15.64^{\mathrm{a}}$ & $14.21 \pm 10.87^{\mathrm{ab}}$ & $13.76 \pm 98.76^{\mathrm{b}}$ & \\
\hline
\end{tabular}




\section{Performance and haematological profile of cockerel chickens}

Table 4: Haematological profile of cockerels debeaked at different ages

\begin{tabular}{lllll}
\hline Parameters & Week 4 & Week 6 & Week 8 & Week 10 \\
\hline PCV & $25.33 \pm 1.26$ & $26.11 \pm 1.55$ & $23.00 \pm 1.43$ & $21.78 \pm 1.23$ \\
HB & $8.10 \pm 0.54$ & $8.71 \pm 0.51$ & $7.68 \pm 0.48$ & $7.26 \pm 0.42$ \\
RBC & $4.09 \pm 0.20$ & $4.04 \pm 0.22$ & $3.66 \pm 0.13$ & $3.68 \pm 0.13$ \\
WBC & $21.59 \pm 1.48$ & $19.78 \pm 1.31$ & $18.47 \pm 0.93$ & $18.33 \pm 1.35$ \\
LYMP & $61.67 \pm 3.14$ & $59.44 \pm 2.19$ & $55.29 \pm 3.88$ & $62.22 \pm 3.66$ \\
Hetero & $31.78 \pm 3.35$ & $33.89 \pm 1.83$ & $36.71 \pm 3.46$ & $31.89 \pm 3.58$ \\
Mono & $3.44 \pm 0.24$ & $3.22 \pm 0.32$ & $3.57 \pm 0.48$ & $2.67 \pm 0.29$ \\
Eosi & $3.00 \pm 0.53$ & $3.22 \pm 0.43$ & $4.29 \pm 0.75$ & $3.00 \pm 0.24$ \\
Baso & $0.22 \pm 0.00$ & $0.22 \pm 0.15$ & $0.14 \pm 0.15$ & $0.00 \pm 0.14$ \\
Platelets X 10 & $14.42 \pm 16.85$ & $15.74 \pm 12.13$ & $13.48 \pm 12.70$ & $15.42 \pm 15.87$ \\
\hline a: means with the same superscripts on the same column are not significantly different $(\mathrm{P}<0.05)$.
\end{tabular}

Table 5: Heterophil-Lymphocyte ratio (H:L) as indices for stress levels in debeaked cockerels:

\begin{tabular}{lllll}
\hline Weeks & $\mathrm{T}_{1}$ & $\mathrm{~T}_{2}$ & $\mathrm{~T}_{3}$ & $\mathrm{~T}_{4}$ \\
\hline Week 4 & 0.7 & 0.4 & 0.6 & 0.5 \\
Week 6 & 0.7 & 0.5 & 0.7 & 0.5 \\
Week 8 & 0.7 & 0.6 & 0.9 & 0.5 \\
Week 10 & 0.7 & 0.5 & 0.6 & 0.4 \\
\hline
\end{tabular}

Also, it was observed that T2 had the highest value of White Blood Cells, Eosinophil and Platelet across the treatments, followed by T3, but T1 had the lowest value of White Blood Cells, Basophil and Platelet across the treatments. From Table 4, it was observed that there were no significance differences $(\mathrm{p}>0.05)$ among all the weeks with regards to all the haematological parameters being examined as this is indicated in the gradual reduction in the levels of blood parameters across all the weeks tested. Also was a progressive reduction was observed in the counts of the defensive mechanism of the blood with regards to the White Blood Cells, Lymphocytes, Monocytes, Red Blood Cells and Basophiles with increasing weeks of debeaking while Table 5 revealed that the $\mathrm{H}: \mathrm{L}$ of T2 and T4 fell within the optimal level of stress as reported by (Altan, 2000). Then T1 and T3 fell within the high degrees of stress respectively across all the ages tested according to the recommendations of (Bilgili and Hess, 1995) which affected the growth performance of the experimental birds.

\section{Conclusion}

It is therefore concluded that farmers should imbibe the practice of cutting half of the upper beak and half of the lower beak or one third of the upper beak and half of the lower beak $\left(\mathrm{T}_{2}\right)$ at the earlier stage of the birds' life preferably $\left(\mathrm{T}_{4}\right)$ at the fourth week or the sixth week as they gave better values for the performance parameters considered.

\section{References}

Altan, K. 2000. Low degree of stress to optimum degree of stress in the 'turkey: an American stong.' University of ilinois press. Pp. 4-5,17. ISBN 978-0-2-5203163-2.

Bilgili, S. F. and Hess, I. B. 1995. Placement density influences on broiler carcass grade and meat yields. I. Appl. Poultry. 41:113 1134.

Gentle, M. J., Hughes, B. O., Fox, A. and Waddngton, D. 1997. Behavioural and anatomical consequences of two beak trimming methods in 1 and 10 day old chicks. British Poultry Science. 38:453-463.

Glatz, P. C. 2005. What is beak-trimming 


\section{Bolarinwa, Adeyemo and Awodele}

and why are birds trimmed? Pages 1-17 in Poultry Welfare Issues: Beak Trimming. P.C. Glatz, ed. Nottingham University Press, UK.

Keeling, L. J., Hughes, B. O. and Dun, P. 1988. Performance of free range laying hens in a polythene house and their behaviour on range. Farm Build. Progr.94:21-28.

Marchant-Forde, R. M., Fahey, A. G. and Cheng, H. W. 2011. Comparative effects of infrared and one-third hot- $\quad$ b 1 a $d$ e trimming on beak topography, behavior, and growth. Poultry Science. 87:1474-1483.
Pizzolante, C. C., Garcia, E. A., Saldanha, E. S. P. B., Langana, C., Faitarona, A. B. G., Souza, H. B. A. and Pelicia, K. 2011. Beak trimming methods and their effects of the performance and egg quality of Japanese quails during lay. Braz. J. Poult Sci. 6:17-21.

Jain, N. C. 1993. Essentials of vet haematology. Philadephia. Lea and Fabigers, Pg 20-86.

SAS/STAT ${ }^{\text {. }}$ 1988. Statistical Analytical System, User's Guide, Release 6.03 Edition 1988. SAS Inst.,Inc., Caty, NC.

Received: $9^{\text {th }}$ February, 2017 Accepted: $20^{\text {th }}$ July, 2017 